\title{
Wound oozing after total hip arthroplasty
}

\author{
JAMES J WOOD ${ }^{1}$, PAUL M BEVIS ${ }^{2}$, GORDON C BANNISTER ${ }^{1}$
}

\author{
${ }^{1}$ Avon Orthopaedic Centre and ${ }^{1}$ Department of General Surgery, Southmead Hospital, Bristol, UK
}

\section{ABSTRACT}

INTRODUCTION Total hip arthroplasty is a commonly performed operation and yet little information exists about the duration of wound oozing, the factors associated with this and the implications. The aim of this work was to identify factors influencing wound oozing by establishing their effect on the time taken for wounds to cease oozing after total hip arthroplasty.

PATIENTS AND METHODS Sixty-two consecutive patients undergoing total hip arthroplasty were included. Wounds were examined for wound oozing on a daily basis by the same observer and were then re-dressed. The time taken for each wound to become dry was recorded. Data were analysed to determine if the time-to-dryness was influenced by wound length, body mass index, estimated volume of blood in the dissected tissues, duration of surgery and ASA grade.

RESULTS Time to dryness was associated with wound length $(P=0.01)$, body mass index (BMI, $P=0.05)$, estimated volume of blood in dissected tissues $(P=0.05)$ and length of hospital stay $(P=0.02)$. No association was found with duration of surgery or ASA grade.

CONCLUSIONS A small-incision, meticulous haemostasis at surgery and a reduction in pre-operative obesity reduce the time taken for hip arthroplasty wounds to become dry. Prolonged wound oozing delays hospital discharge.

\section{KEYWORDS}

Total hip arthroplasty - Wound oozing

\section{CORRESPONDENCE TO}

James Wood, c/o Mr Bannister's secretary, Avon Orthopaedic Centre, Southmead Hospital, Bristol BS10 5NB, UK,

E: jimwood@doctors.net.uk

Total hip arthroplasty is a commonly performed operation. However, little data exist about surgical and patient factors that influence wound healing. Fluid oozes from wounds during healing. Prolonged fluid ooze may delay discharge from hospital. It was hypothesised that factors influencing the length of time that a wound would ooze following total hip arthroplasty might include wound length, estimated volume of blood into the dissected tissues, body mass index (BMI), duration of surgery and ASA grade.

\section{Patients and Methods}

Consecutive patients undergoing primary total hip arthroplasty over a 3-month period were included in the study. The study did not implement any changes to the standard pre, peri- and postoperative management. As part of the routine pre-operative assessment, each patient had blood taken for haemoglobin and haematocrit measurement. Height and weight were recorded and BMI calculated. As part of routine postoperative management, each patient had a haemoglobin and haematocrit check on the first postoperative day.
Dressings were changed on a daily basis and examined by the same observer for the presence of wound ooze. It was noted whether the fluid ooze was serous, serosanguinous, blood or pus and whether the wound gaped. The length of the wound was measured. The amount of intra-operative blood loss was identified from the anaesthetic record and the amount of fluid in the drain was noted.

The red blood cell (RBC) volume lost into the tissues was estimated from a formula described by Sehat et al: ${ }^{1}$

RBC volume loss $(\mathrm{ml})=$

$$
\begin{array}{r}
{\left[\mathrm{PBV} \times\left(\mathrm{Ht}_{1}-\mathrm{Ht}_{2}\right)\right]-[(\text { drain loss }+ \text { theatre loss }) \times} \\
(\text { mean } \mathrm{Ht})]+[\mathrm{T} \times 200]
\end{array}
$$

where PBV was the estimated circulating patient blood volume, $\mathrm{Ht}_{1}$ and $\mathrm{Ht}_{2}$ were pre- and postoperative haematocrits, respectively, and $\mathrm{T}$ was the number of units of blood transfused. A oneunit blood transfusion contained a standard $200 \mathrm{ml}$ of RBCs. Estimated PBV was $75 \mathrm{ml} / \mathrm{kg}$ for men and $65 \mathrm{ml} / \mathrm{kg}$ for women. The RBC volume was converted to whole blood volume using the mean haematocrit. 


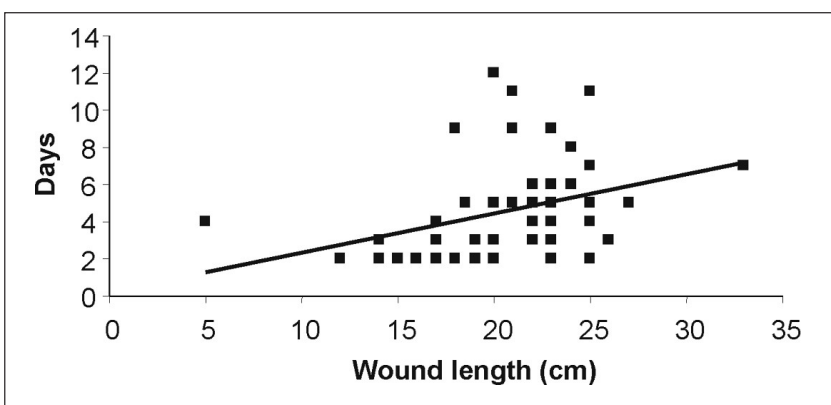

Figure 1 Relationship of wound length to days to dryness (correlation coefficient $0.35 ; P=0.01$ ).

Graphs were plotted showing the relationship between timeto-dryness and wound length, estimated volume of blood in tissues, BMI and duration of surgery. The method of least squares was used to fit a straight line to these graphs. Linear regression analysis was used to calculate the slopes, correlation coefficients and standard errors of the slopes. A $t$-test was used to test the null hypotheses that the slopes were actually equal to zero.

A graph was also plotted showing the relationship between time-to-dryness and hospital stay. A Spearman rank test was used to estimate the correlation and a $t$-test was used to test the null hypothesis that the correlation coefficient was actually equal to zero.

\section{Results}

Sixty-two patients were enrolled over the study period. Wounds were closed with deep vicryl to fascia and fat and skin clips $(81 \%)$ or subcuticular sutures $(19 \%)$. One patient had a prolonged hospital stay and eventually died due to a perforated sigmoid colon. This patient had prolonged wound ooze but was excluded from the study in view of the serious concurrent medical problems. The median time taken for wounds to become dry was 4 days (interquartile range, 3-6 days). There were no gaping wounds.

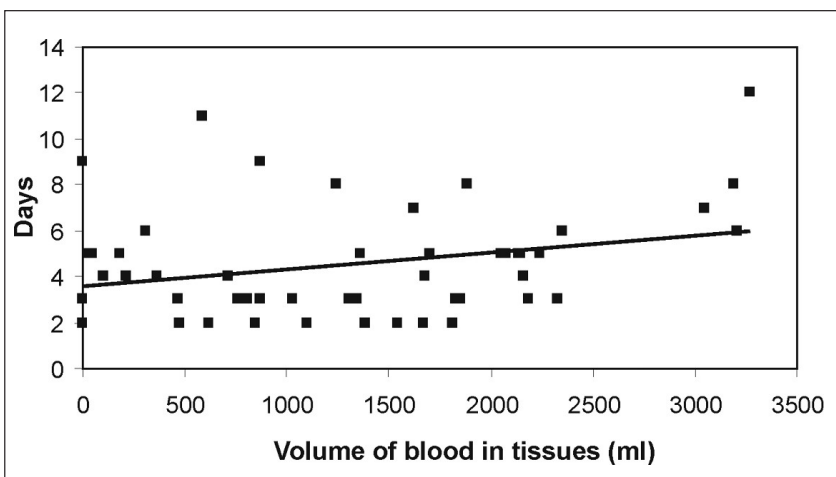

Figure 3 Relationship of estimated quantity of blood in tissues to days to dryness (correlation coefficient $0.28 ; P=0.05$ ).

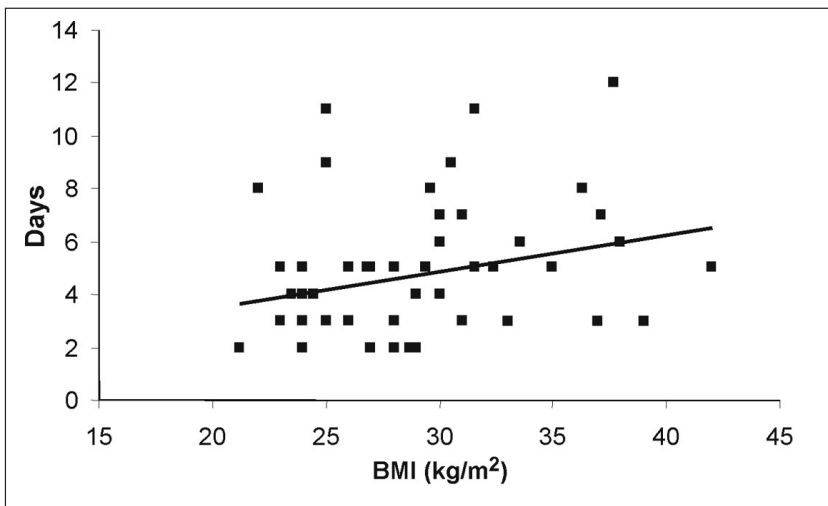

Figure 2 Relationship of body mass index to days to dryness (correlation coefficient $0.24 ; P=0.05$ ).

Figures 1-3 are scatter plots showing the relationship between time-to-dryness and wound length, BMI and estimated volume of blood in dissected tissues, respectively. Length of incision, BMI and estimated volume of blood in tissues were associated with duration of wound oozing $(P=0.01$, $P=0.05$ and $P=0.05$, respectively). There was an association between time-to-dryness and length of hospital stay $(P=0.02$; Fig. 4). There was no association between wound length and BMI, blood in tissues and BMI, or wound length and blood in tissues. There was no association between time-to-dryness and duration of surgery, ASA grade or method of skin closure and no trend to any association.

\section{Discussion}

It is probable that the time taken for a wound to cease oozing relates to wound healing time. It is likely that wound oozing is due to haemolysis of subcutaneous blood. This study shows that the time taken for wounds to stop oozing following total hip replacement is significantly related to the length of the incision, body mass index and estimated volume of blood in the dissected tissues. Wound oozing lengthens hospital stay.

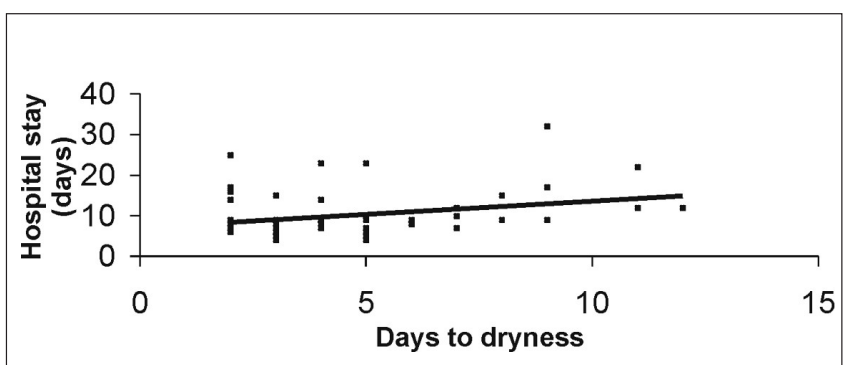

Figure 4 Relationship of length of hospital stay to days to dryness (correlation coefficient $0.29 ; P=0.02$ ). 
There have been no similar studies comparing wound ooze with wound length for conventional open total arthroplasty. However, Woolston et al. ${ }^{2}$ showed that there was no difference in wound healing for primary total hip replacements performed through a standard incision compared to a 'mini-incision' with a wound length less than $10 \mathrm{~cm}$. They also found no difference in blood loss, transfusion rate or length of hospital stay. Their methodology differs to our study in that all but one of our wound incisions were greater than $10 \mathrm{~cm}$. In addition, we estimated the quantity of blood in tissues and not only intra-operative blood loss.

Previous studies have examined factors which may influence wound healing. Obesity is a risk factor for wound infection and incisional herniae in mid-line laparotomy wounds. ${ }^{3}$ Skin staples compared to the use of nylon sutures cause more inflammation and discomfort but do not impair wound healing. ${ }^{4}$

\section{Conclusions}

A small incision, reduction in pre-operative obesity and meticulous haemostasis at surgery reduces the time taken for wounds to become dry following total hip arthroplasty. Prolonged wound oozing delays hospital discharge.

\section{References}

1. Sehat KR, Evans RL, Newman JH. Hidden blood loss following hip and knee arthroplasty. J Bone Joint Surg Br 2004; 86: 561-5.

2. Woolston ST, Mow CS, Syquia JF, Lannin JV, Schurman DJ. Comparison of primary total hip replacements performed with a standard incision or a min-incision. J Bone Joint Surg Am 2004; 86: 1353-8.

3. Israelsson $L A$, Jonsson $T$. Overweight and healing of midline incisions: the importance of suture technique. Eur J Surg 1997; 163: 175-80.

4. Stockley I, Elson RA. Skin closure using staples and nylon sutures: a comparison of results. Ann R Coll Surg Engl 1987; 69: 76-8.

This publication is copyright under the Berne Convention and the International Copyright Convention. All rights reserved. Apart from any relaxations permitted under national copyright laws, no part of this publication may be reproduced, stored in a retrieval system or transmitted in any form or by any means without the prior permission of the copyright owners. Permission is not, however, required to copy abstracts of papers or of articles on condition that a full reference to the source is shown or to make single photocopies of articles provided the copy is for the personal use of the copier or of a client library. Multiple copying of any of the contents of the publication without permission is always illegal.

Advertisements. All communication should be addressed to ADmedica, Stevenson, Haddington, East Lothian EH41 4PU, UK. T: 0162082 3383, F: 0162082 3325, E: pnoble@admedica.co.uk.

While every effort is made by the publishers and Editorial Committee to see that no inaccurate or misleading opinion or statement appears in this journal, they wish to make it clear that the opinions expressed in these articles, correspondence, advertisements, etc, herein are the responsibility of the contributor or advertiser concerned. Accordingly, the publishers and the Editorial Committee and their respective employees, officers and agents accept no liability whatsoever for the consequences of any such inaccurate or misleading opinion or statement.

Published by The Royal College of Surgeons of England, 35-43 Lincoln's Inn Fields, London WC2A 3PE, UK. Registered Charity No 212808

Printed and bound in Great Britain by HOBBS The Printers, Brunel Road, Totton, Hampshire SO40 3WX, UK

Typesetting and editorial services: B.A. \& G.M. Haddock, Woodlands, Ford, Midlothian EH37 5RE, Scotland, UK

Subscription information: From 2007, the Annals of The Royal College of Surgeons of England (ISSN 0035-8843) is published 8 times a year in January, March, April, May, July, September, October and November.

The non-member subscription prices for Volume 89 (2007), including postage by surface mail (full airmail £35/US\$59 extra), are: Standard subscription (print + free online) $\quad$ Individual: $£ 145$ (Europe), US\$248 (USA), £156 (Rest of world) (Single copies $£ 25$ ) Institution: $£ 166$ (Europe), US\$304 (USA), £178 (Rest of world)

Online-only subscription: $£ 147$ (Europe and Rest of world $+£ 25.73$ VAT) or US $\$ 273+$ VAT (USA). Online only may be subject to VAT. For all customers based in the UK, and customers in other EU countries who do not provide their local VAT registration number, UK VAT at $17.5 \%$ is payable in addition. Further details about accessing the journal online can be found at: www.portlandpress.com/pcs/journals/journal.cfm?product=ARCS.

Orders are regarded as firm and payments are not refundable. Subscriptions at Individual rates must be paid for by personal cheque/ credit card. All orders and enquiries concerning subscriptions and back issues should be sent to Portland Customer Services, Portland Press Ltd, Commerce Way, Colchester CO2 8HP, UK (Tel +44 (0)1206 796351; Fax +44 (0)1206 799331; Email: sales@rportland-services.com). Claims must be made within 6 months of publication or date of order, whichever is the later. 